\title{
Therapeutic Management of Leptospirosis in Two Dogs: A Case Report
}

\author{
Pankaj Kumar Patel ${ }^{1}$, Sawita Kumari Patel ${ }^{2}$, Naveen Kumar Verma ${ }^{3}$ and S.K. Dixit ${ }^{\text {* }}$ \\ ${ }^{1}$ Division of medicine, ICAR-Indian Veterinary Research Institute, Izatnagar-243122, India \\ ${ }^{2}$ Division of Veterinary Public Health, ICAR-Indian Veterinary Research Institute, \\ Izatnagar-243122, India \\ ${ }^{3}$ Division of Surgery, ICAR-Indian Veterinary Research Institute, Izatnagar-243122, India \\ *Corresponding author
}

\section{A B S T R A C T}

This report deals with the successful clinical management of Leptospirosis infection in two dogs. Two dogs one Pomeranian and one Labrador of ages two years and four years respectively was presented to the Referral Veterinary Polyclinic, IVRI Izatnagar in recumbent stage having history of acute onset of vomiting, anorexia, polydipsia, polyuria

Keywords

Therapeutic management, Dogs

Article Info

Accepted:

24 February 2018

Available Online:

10 March 2018 and weight loss, coughing, lethargy. There were no proper record of deworming and vaccination. Clinical examination revealed icteric conjunctival, gingival and penile mucous membrane, fever, depressed mentation, enlarged lymph node, tachycardia and tachypnea and slightly distended abdomen, Abdominal palpation and ultrasonographic examination revealed hepato-renal abnormality and Superficial lymph nodes (popliteal, and submandibular) were greatly enlarged. The hemato-biochemical report showed a marked reduction in $\mathrm{Hb}$, TEC, PCV, hypoalbuminemia and elevated SGPT, SGOT, BUN, Creatinine and ALP level. Blood smear examination was negative for hemoprotozoan infection. Serum sample of the dogs was positive for Ab titre during MAT. Based on clinical signs and laboratory findings the case was diagnosed as Leptospirosis in dogs having hepato-renal complications. Following the diagnosis of the case, treatment was started with Amoxicillin-clavulanate for 15 days followed by doxycycline next 15 days along with supportive treatment. Both animals start recovering from $15^{\text {th }}$ day onward. Both animals recovered uneventfully after treatment.

\section{Introduction}

Leptospirosis is an acute or chronic contagious zoonotic disease caused by strictly aerobic gram-negative spirochetes belonging to the genus Leptospira, which is transmitted through the infected urine that affects humans as well as wide range of animals and its severity depends on the virulence of the organism, susceptibility of the host, and the affected host species (Radostits, et al., 2000). L. interrogans sensu lato is having numerous antigenically divergent serovars that responsible for the disease in dogs and their common reservoirs include L. canicola (dog), L. icterohaemorrhagiae (rodents) (Greene et al., 1998). It is modest or nil cross-immunity between Leptospira serovars (Greene and others 2006), therefore no vaccination protocol can, at present, provide protection 
against these new serovars. Diagnosis of leptospirosis is done by using history, clinical findings and laboratory findings. serum samples are send for serological testing for confirmatory diagnosis. The first line of treatment of leptospirosis is to provide the dogs with the penicillin class of antibiotics along with fluid therapy are giving to as supportive care (Adin, et al., 2000).

This study represents the diagnosis and successful management of leptospirosis infection in both cases.

\section{Case history and Clinical examination}

A two-year-old male Pomeranian(case no.1) and a four-year male Labrador (case no. 2) dog was presented to the Referral Veterinary polyclinic, Indian Veterinary Research Institute, Izatnagar, Bareilly (U.P.) having the history of vomiting, anorexia, polydipsia, polyuria, coughing and weight loss.

Both animals were recumbent since two days. There was no previous history of deworming and vaccination the animal was treated in the local veterinary clinic since 1 week having no improvement.

On clinical examination dogs had depressed mentation, slightly icteric conjuctival and gingival mucous membrane and were reluctant to rise. Animal had markedly icteric penile mucous membrane, slight rise in rectal temperature, tachycardia and tachypnea and slightly distended abdomen. Ultrasonographic examinations revealed hepato-renal abnormalities (Fig. 1 and 2). On palpation superficial lymph nodes (popliteal and submandibular) were found greatly enlarged.

Differential diagnosis was done to rule out the possibilities of other hemoprotozoan infections (Babesia gibsoni, Babesia canis and Ehrlichia canis).

\section{Diagnosis}

Diagnosis was done through history, clinical sign, hematology, serum chemistry and serology. The hemato-biochemical report revealed a marked reduction in $\mathrm{Hb}$, TEC, PCV, hypoalbuminemia and elevated SGPT, SGOT, BUN, Creatinine and ALP level (Table 1 and 2). Peripheral blood smear examination was found negative for hemoprotozoan infection.

\section{Confirmatory diagnosis}

A serum samples were sent for Leptospira specific MAT (Microscopic Agglutination Test) and LAT (Latex Agglutination Test, recently developed at IVRI) test for the confirmation. Serum samples were found positive for Ab titre by MAT. LAT revealed agglutination within 3 seconds indicating merely heavy infection of Leptospira. Although thrombocytopenia and corneal opacity due to uveitis are rare in the dog having leptospirosis, but these were evident in one case.

\section{Treatment}

Treatment was started with fluid therapy in the form of normal saline and Haemaccel @ 10 $\mathrm{ml} / \mathrm{kg}$ body weight was given hemoglobin level was low. Amoxicillin-clavulanate @ $15 \mathrm{mg} / \mathrm{kg}$ body weight intravenously BID for 15 days followed by doxycycline (@5.0 $\mathrm{mg} / \mathrm{kg}$ body weight orally BID for next 15 days. An immunosuppressive dose of predenisolone was given @ $0.5 \mathrm{mg} / \mathrm{kg}$ body weight orally once in a day for 5 days followed by $0.25 \mathrm{mg} / \mathrm{kg}$ orally for next 3 days. To prevent thromboembolism, aspirin @ 2 $\mathrm{mg} / \mathrm{kg}$ body weight once in a day for 5 days was given. Along with the above treatment Antioxidant therapy (Vitamin E @ 400 IU orally every day, Vitamin C @ 200 mg orally twice a day and N-Acetyl cysteine @ 60-70 
$\mathrm{mg} / \mathrm{kg}$ body weight slow IV, Antiemetics (Ondansetron@0.5 mg/kg body weight IV twice in a day for 2 days), Gastroprotectans (Pantoprazole @ $1 \mathrm{mg} / \mathrm{kg}$ body weight IV OD for 5 days followed by sucralfate @ 1g orally every 12 hour for 7 days) and Hematinics [Iron (Imferon) injection IM @ 1ml every 5 day (total 4 injection), syrup haemup (1 tsf orally twice in a day for 15 days] was given. Supportive treatment included syrup Livo ${ }^{+}$ (Sylimarin and Ornithine) @ 1 tsp orally twice in a day, vitamin $\mathrm{K} 1$ injection on an alternate day, lactulose @ 5ml orally for 5 days to maintain ammonia level.

\section{Results and Discussion}

There was no significant improvement noticed in the condition during first two days, but after 5 days treatment dog showed some improvement. Now the dogs were able to stand but often stumble while walking and started taking some food. After 10 days of treatment, the animal condition was quite improved. Icteric penile mucous membrane started appearing pale yellowish with the slightly pale conjunctival mucous membrane. Haemato-biochemical examination on 21th day showed normal haemato-biochemical values. Both case recovered well after 30 days of treatment.

Leptospirosis in dogs is classified as peracute, subacute, acute and chronic. Acute leptospirosis is characterized by Pyrexia (103$104^{\circ} \mathrm{F}$ ), shivering, and generalized muscle tenderness (myalgia) followed by vomiting, rapid dehydration, and peripheral vascular collapse subsequently (Greene, 1998). It generally affects 1-6 years age group animals. In dogs, the incubation period varies between 3 and 20 days; the most common signs of disease are anorexia, lethargy, vomiting, fever, weight loss, polydipsia, polyuria, diarrhea, abdominal/lumbar pain, icterus/jaundice, stiffness/reluctance to walk (myalgia), enlarged kidneys (renomegaly), petechiae or sometimes severe hemorrhage. Lymphadenopathy, low platelet count (thrombocytopenia) and Uveitis is an uncommon manifestation of Leptospirosis in dogs (Pareck manual $11^{\text {th }}$ addition). Haemolytic anaemia is not a common feature of canine leptospirosis (Sykes et al., 2011). Liver damage is demonstrated by increased serum alanine aminotransferase (ALT), aspartate aminotransferase, lactate dehydrogenase, and alkaline phosphatase (ALP) activities. Bilirubin concentration also is increased, reflecting cholestasis. The increase in serum ALP activity often is proportionally greater than that of ALT activity. Increased serum amylase and lipase activities may result from their release from inflamed hepatic and small intestinal tissues and from decreased renal clearance (Khan et al., 2009). A wide variety of serological tests, which show varying degrees of serogroups and serovar specificity, have been described. In veterinary two tests are of diagnostic importance: the microscopic agglutination test (MAT) and enzyme-linked immunosorbent assay (ELISA) (OIE, 2000). Both BUN and creatinine were elevated suggesting kidney damage and serum biochemical profiles with liver damage are elevated ALP, ALT and bilirubin (Chang et al., 2007).

In the acute stage of the Leptospirosis "Microscopic Agglutination Test" (L-MAT) is the currently recognized as "gold standard" diagnostic test. Titer is low in the acute stage of infection and then rise in the restorative sample to $1: 800-1: 1600$ or higher if animal is previously vaccinated by homologous Leptospira serovar but in vaccinated animals, expect low (usually not higher than 1:400) titers for the vaccine serovars L. canicola and L. icterohaemorrhagiae, and for other serovars the above information is the same; if possible, all the serum samples should be run at the same time (Baldwin, et al., 1987). 
Case no. 1
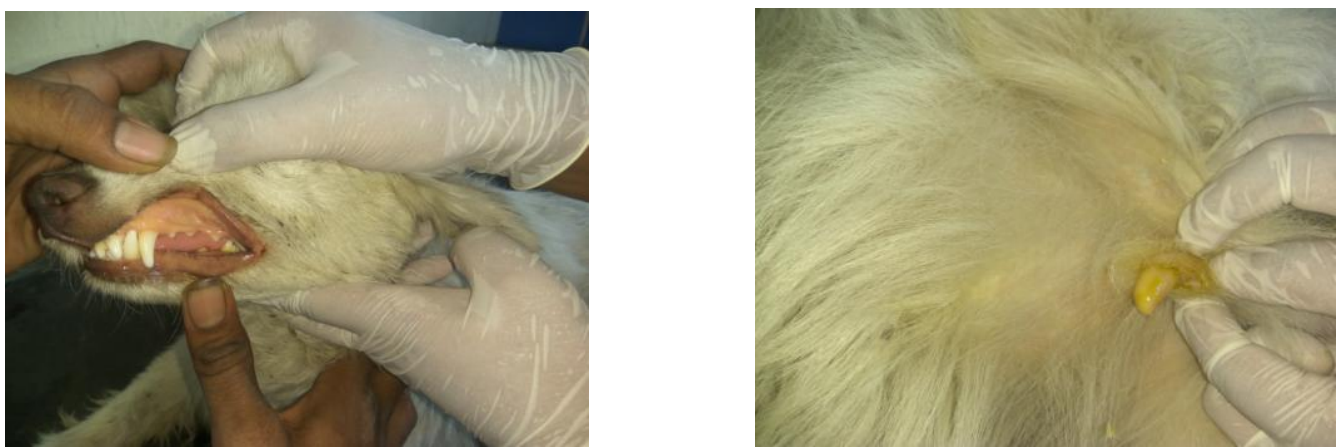

Case no.2
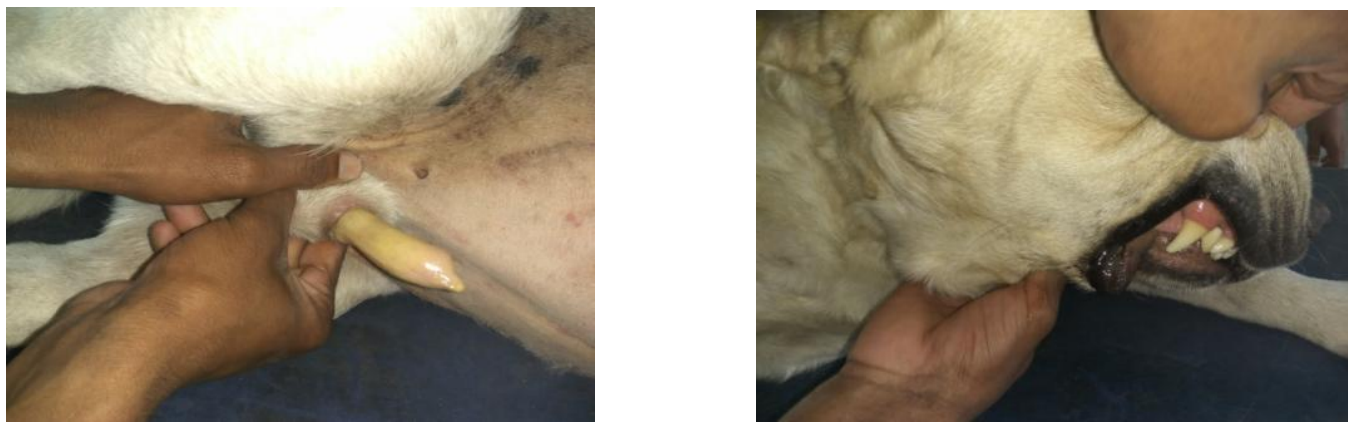

Fig.1 Hepatomegaly and hepatic congestion

Fig.2 Hyperechoic renalcortex
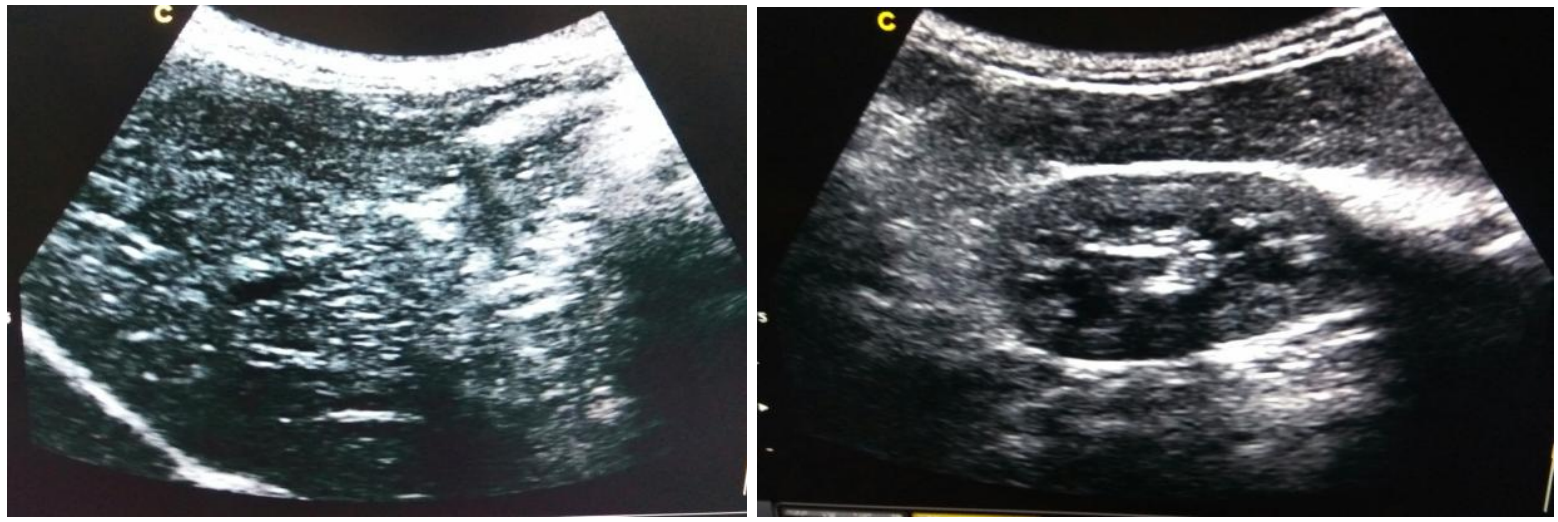

Ultrasonographic examination

Latex agglutination test (LAT)
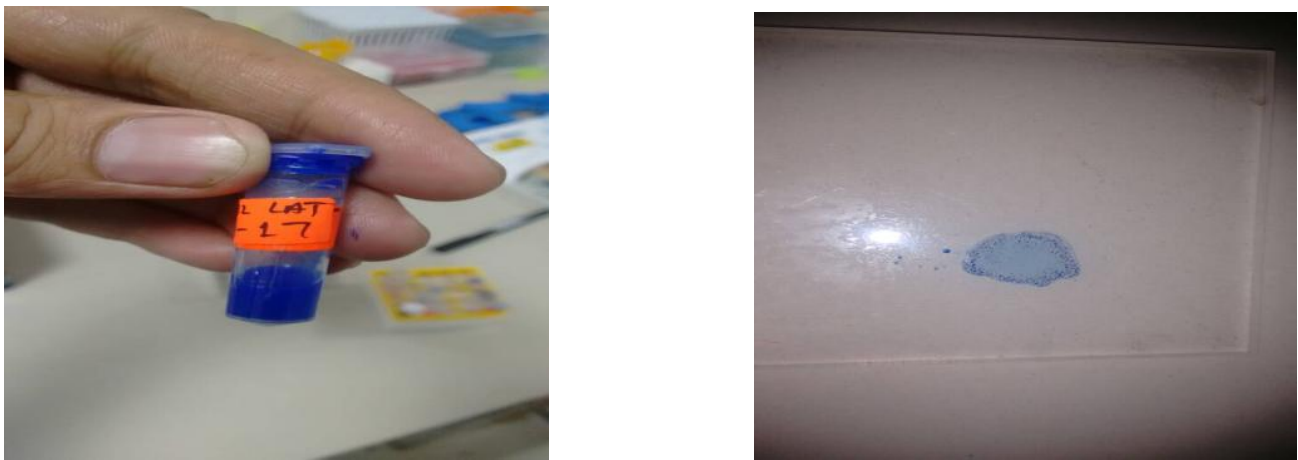
Table.1 Detailed haematological examination of both cases

\begin{tabular}{|c|c|c|c|c|c|c|c|}
\hline \multirow{2}{*}{$\begin{array}{l}\text { Haematological } \\
\text { parameter }\end{array}$} & \multirow[b]{2}{*}{$\begin{array}{l}\text { Reference range } \\
\text { (Merck } \\
\text { Veterinary } \\
\text { Manual 11 } \\
\text { addition) }\end{array}$} & \multicolumn{2}{|c|}{0 day } & \multicolumn{2}{|c|}{$5^{\text {th }}$ day } & \multicolumn{2}{|c|}{$21^{\text {th }}$ day } \\
\hline & & $\begin{array}{l}\text { Case } \\
\text { no. } 1\end{array}$ & $\begin{array}{l}\text { Case } \\
\text { no.2 }\end{array}$ & $\begin{array}{l}\text { Case } \\
\text { no. } 1\end{array}$ & $\begin{array}{l}\text { Case no. } \\
\quad 2\end{array}$ & $\begin{array}{c}\text { Case no. } \\
1\end{array}$ & $\begin{array}{c}\text { Case no. } \\
\quad 2\end{array}$ \\
\hline $\mathrm{Hb}(\mathrm{g} / \mathrm{dl})$ & $11.9-18.9$ & 6.5 & 5.6 & 7.1 & 6.0 & 11.7 & 10.6 \\
\hline PCV (\%) & $24-46$ & 18.4 & 16.7 & 19.6 & 17.2 & 28 & 24 \\
\hline $\begin{array}{c}\text { TEC } \\
\left(10^{6} / \mathrm{cmm}\right)\end{array}$ & $4.95-7.87$ & 3.5 & 2.81 & 4.0 & 3.29 & 5.85 & 4.65 \\
\hline $\begin{array}{c}\text { TLC } \\
\left(10^{3} / \mathrm{cmm}\right) \\
\end{array}$ & $5.0-14.1$ & 24.5 & 22.2 & 21.5 & 24.0 & 16.8 & 15.2 \\
\hline Neutrophils \% & $58-85$ & 80 & 81 & 77 & 80 & 70 & 68 \\
\hline $\begin{array}{c}\text { Lymphocytes } \\
\%\end{array}$ & $8-21$ & 20 & 19 & 27 & 20 & 28 & 29 \\
\hline Monocytes\% & $2-10$ & 3 & 0 & 2 & 0 & 1 & 2 \\
\hline Eosinophils\% & $0-9$ & 3 & 0 & 0 & 0 & 1 & 1 \\
\hline Basophil\% & $0-1$ & 0 & 0 & 0 & 0 & 0 & 0 \\
\hline $\begin{array}{l}\text { Platlet count } \\
\left(10^{6} / \mathrm{cmm}\right)\end{array}$ & $211-621$ & 160 & 63 & 168 & 177 & 240 & 284 \\
\hline
\end{tabular}

Table.2 Detailed biochemical examination of both cases

\begin{tabular}{|c|c|c|c|c|c|c|c|}
\hline \multirow{2}{*}{$\begin{array}{l}\text { Biochemical } \\
\text { parameter }\end{array}$} & \multirow[b]{2}{*}{$\begin{array}{l}\text { Reference } \\
\text { range (Merck } \\
\text { Veterinary } \\
\text { Manual 11 } \\
\text { addition) }\end{array}$} & \multicolumn{2}{|c|}{0 day } & \multicolumn{2}{|c|}{$5^{\text {th }}$ day } & \multicolumn{2}{|c|}{21 day } \\
\hline & & $\begin{array}{l}\text { Case } \\
\text { no.1 }\end{array}$ & $\begin{array}{l}\text { Case } \\
\text { no.2 }\end{array}$ & $\begin{array}{l}\text { Case } \\
\text { no.1 }\end{array}$ & $\begin{array}{l}\text { Case } \\
\text { no.2 }\end{array}$ & $\begin{array}{l}\text { Case } \\
\text { no.1 }\end{array}$ & $\begin{array}{l}\text { Case } \\
\text { no.2 }\end{array}$ \\
\hline SGPT(U/L) & $10-109$ & 242 & 247 & 134 & 108 & 68 & 49 \\
\hline SGOT (U/L) & $13-15$ & 195 & 119 & 88 & 78 & 52 & 37 \\
\hline BUN (mg/dl) & $8-28$ & 60 & 47 & 33 & 40 & 27 & 13 \\
\hline Creatinine $(\mathrm{mg} / \mathrm{dl})$ & $0.5-1.7$ & 5.6 & 2.88 & 3.88 & 2.6 & 1.3 & 0.8 \\
\hline $\begin{array}{ll}\text { total } & \text { Protein } \\
(\mathrm{mg} / \mathrm{dl}) & \\
\end{array}$ & $5.4-7.5$ & 3.9 & 6.6 & 5.2 & 7.5 & 7.1 & 7.0 \\
\hline Albumin (mg/dl) & $2.3-3.1$ & 0.9 & 2.6 & 2.1 & 1.9 & 3 & 2.7 \\
\hline Globulin $(\mathrm{mg} / \mathrm{dl})$ & $2.7-4.4$ & 3 & 4 & 3.1 & 5.6 & 3.1 & 3.3 \\
\hline $\mathrm{A}: \mathrm{G}$ & $0.85-0.70$ & 0.3 & 0.65 & 0.68 & 0.34 & 0.97 & 0.82 \\
\hline ALP (U/L) & $1-114$ & 1800 & 2591 & 1640 & 2219 & 150 & 119 \\
\hline $\begin{array}{ll}\text { Total } & \text { Billirubin } \\
(\mathrm{mg} / \mathrm{dl}) & \end{array}$ & 0.3 & 1.9 & 1.69 & 0.9 & 2.0 & 0.3 & 0.5 \\
\hline $\begin{array}{ll}\text { Direct } & \text { Billirubin } \\
(\mathrm{mg} / \mathrm{dl}) & \\
\end{array}$ & & 1.5 & 1.03 & 0.5 & 1.4 & 0.2 & 0.2 \\
\hline
\end{tabular}


The fourfold rise in antibody titer of Leptospira serovar is considered significant. When titers to a particular serovar reach high levels, e.g., 1:3200 to 1:6400, it is not unusual to see elevated titers to other serovars, which is likely due to cross-reactions.

Development of antibody titer is negatively affected by the antimicrobial agent (Chang et al., 2007). Due to significant interlaboratory variation in MAT results, thus MAT does not perfectly predict the infecting serogroup (Sykes et al., 2011).

Leptospirosis infected dogs with initially treated with a penicillin derivative antibiotics (amoxicillin@20-30 mg/kg QID) for 14 days followed by dogs treated with doxycycline @ $5 \mathrm{mg} / \mathrm{kg}$ orally twice in a day for next 14 days (Schuller et al., 2015). Successfully clearance of the Leptospira from renal tubules is doxycycline, $5 \mathrm{mg} / \mathrm{kg}$ orally twice in a day, for 14 days (Sykes et al., 2011).

Vitamin $\mathrm{C}$ is the only antioxidant that gives complete protection from oxidative damage (Polidori et al., 2004). Low serum vitamin C concentration leads to lipid peroxidation (Ulutas et al., 2006). N-acetylcysteine increases hepatorenal perfusion and improve their function and Sylimarin significantly affects the serum SGPT, SGOT, Alkaline phosphatase activities, serum urea and creatinine levels and maintains malondialdehyde level (MDA) as an antioxidant in liver and kidney (El-Maddawy et al., 2012).

Leptospirosis in dogs generally occurs 1-6 years age group unvaccinated animals. The incubation period varies between 3 and 20 days. Leptospirosis infected dogs will manage by initially treated with amoxicillin for 14 days followed by doxycycline @ $5 \mathrm{mg} / \mathrm{kg}$ orally twice in a day for next14 days along with hepatorenal supportive therapy.

\section{References}

Adin, C. A., Cowgill L. D. 2000. Treatment and outcome of dogs with leptospirosis: 36 cases (1990-1998). JAVMA 216:371-375,

Baldwin, C. J., and Atkins, C. E. (1987). Leptospirosis in dogs. The Compendium on continuing education for the practicing veterinarian (USA).

Chang, Y. F., Chen, C. S., Palaniappan, R. U., He, H., McDonough, S. P., Barr, S. C., and Chang, C. F. (2007). Immunogenicity of the recombinant Leptospiral putative outer membrane proteins as vaccine candidates. Vaccine, 25(48): 8190-8197.

El-Maddawy, Z. K., and Gad, S. B. (2012). Hepato-renal protection of silymarin in comparison with vitamin $\mathrm{E}$ in rats. Glob. J. Pharmacol. 6(3): 236-244.

Greene, C. E., Sykes, Brown J. E., C. A. and Hartmann, K. 2006. Leptospirosis. In Infectious Diseases of the Dog and Cat. 3rd edn. Ed C. E. Greene. St Louis, Saunders Elsevier. 402-417

Greene, C.E., Miller, M. A., Brown, C.A. 1998. Leptospirosis, in Greene CE (ed): Infectious Diseases of the Dog and Cat. Philadelphia, WB Saunders, 273-281.

Khan, S., M. Hassan and G. Yasin. 2009. Acute Leptospirosis in Dog- A case report. The Internet Journal of Veterinary Medicine. 7(2): 1-4.

Merck Veterinary Manual $11^{\text {th }}$ addition

OIE (2000). Manual of standards diagnostic tests and vaccines, leptospirosis, Paris. Part 2, Section 2. 2, Chapter 2. 2. 4. http://www.OIE.int.

Polidori, M. C., Mecocci, P., Levine, M., and Frei, B. 2004. Short-term and long-term vitamin $\mathrm{C}$ supplementation in humans dose-dependently increases the resistance of plasma to ex vivo lipid peroxidation. Arch. Biochem. Biophys. 423(1): 109-115. 
Radostits, O.M., Gay C.C., Blood,D.C., Hinchcliff K.W. 2000. Veterinary Medicine. W.B. Saunders, London,: 971-988.

Schuller, S., Francey, T., Hartmann, K., Hugonnard, M., Kohn, B., Nally, J. E., and Sykes, J. (2015). European consensus statement on leptospirosis in dogs and cats. J. Small Anim. Pract., 56(3): 159-179.

Sykes J. E., Hartmann K., Lunn, K. F., Moore, G. E., Stoddard, R. A, Goldstein R. E. 2011. 2010 ACVIM small animal consensus statement on leptospirosis: diagnosis, epidemiology, treatment, and prevention. Journal of Veterinary Internal Medicine 25: $1-13$

Sykes, J. E., Hartmann, K., Lunn, K. F., Moore, G. E., Stoddard, R. A., and Goldstein, R. E. (2011). 2010 ACVIM small animal consensus statement on leptospirosis: diagnosis, epidemiology, treatment, and prevention. J. Vet. Intern. Med., 25(1): 1-13.

Ulutas, P. A., Bayramli, G., Ulutas, B., Kiral, F., and Atasoy, A. 2006. Oxidative stress and non-enzymatic antioxidant status in dogs with aspirin induced gastric mucosal injury. Rev. Med. Vet., 157(8/9): 401.

\section{How to cite this article:}

Pankaj Kumar Patel, Sawita Kumari Patel, Naveen Kumar Verma and Dixit, S.K. 2018. Therapeutic Management of Leptospirosis in Two Dogs: A Case Report. Int.J.Curr.Microbiol.App.Sci. 7(03): 2966-2972. doi: https://doi.org/10.20546/ijcmas.2018.703.343 